\title{
Some physical results of single electron transitor
}

- Le Hoang Minh

Ho Chi Minh City University of Technology and Education

- Dinh Sy Hien

The University of Science, VNU-HCM

Email:dshien52@yahoo.com

(Received on $20^{\text {th }}$ January 2017, accepted on $15^{\text {th }}$ October 2017)

ABSTRACT

Single electron transistor (SET) is a key element in current research area of nanoelectronics and nanotechnology which can offer nano-feature size, low power consumption and high operating speed. SET is a new nanoscale switching device. It can control the motion of the single electron. The goal of this paper is to discuss about some physical properties of the SET and focuses on simulation of basic quantum device characteristics such as tunneling effect, Coulomb blockage, Quantum dot, Coulomb staircase, and Coulomb oscillation. The current-voltage characteristics of SET are explored for illustration. Two types of metallic and semiconducting SETs have been simulated.

Key words: single electron transistor, current-voltage characteristics, Coulomb blockage, Coulomb staircase, Coulomb oscillation

\section{INTRODUCTION}

Rapid progress in microelectronics has pushed the MOSFET ( dimension toward the physical limit $(10 \mathrm{~nm})$. In the future it is probable that the nano-MOSFETs could be replaced by new fundamental devices such as single electron transistor (SET). SETs have attracted much attention for IC applications because of their nanofeature size, ultra-low power dissipation, high frequency, new functionalities, and CMOS compatible fabrication process [1].

After their discovery in the 1986 [2, 3], there has been extensive research on the fabrication, design and modeling of SETs [4]. SETs with a variety of structures were proposed and fabricated by using different methods [5-7]. SETs have been fabricated to operate at room temperature [8-10]. Molecular quantum dot [11] can display SET's behavior. 1D structures, such as carbon nanotubes and nanowires, can act as SETs [7]. Recent advances in grapheme [12] show promise for SETs.
Research on SET modeling and simulation has been an active area. Monte Carlo simulation has been widely used to model SETs. SIMON [13] and MOSES [14] are the two most popular SET simulators. Uchida et al. proposed an analytical SET model and incorporated it into SPICE [15]. Inokawa et al. extended this model to a more general form to include asymmetric SETs [16]. Mahapatra et al. proposed a simulation framework for hybrid SET/CMOS circuit design and analysis [17]. In contrast, model used non-equilibrium Green's function method (NEGF) [18] commonly used in the nanoscale devices and are superior in terms of simplicity.

In this work, we introduce the physical properties of SET and simulate current-voltage characteristics in single electron transistor by nonequilibrium Green's function method using graphic user interface (GUI) of Matlab. Here, we use a model of one-level (metallic) and multiplelevel (semiconducting) device for SET. We also summarize the theoretical approach based on NEGF, review the capabilities of the simulator, NEMO-VN2 [19], give examples of typical

Trang 206 
TẠP CHÍ PHÁT TRIỂN KHOA HỌC \& CÔNG NGHỆ: CHUYÊN SAN KHOA HỌC TỰ NHIÊN, TậP 1, SỐ 6, 2017

simulations of SET's current-voltage characteristics, and compare simulated results with experimental ones.

\section{PHYSICS, MODELING AND SIMULATION OF THE SINGLE ELECTRON TRANSISTOR}

Basic physical properties of the single electron transistor

The operation of a single electron tunneling device is governed by the Coulomb charging effect. As shown in Fig. 1A, a single electron tunneling device consists of a nanometer-scale conductive (or semiconducting) island embedded in an insulating material. Electrons travel between the island, source (S) and drain (D) through thin insulating tunnel junctions. When an electron tunnels into the island, the overall electrostatic potential of the island increases by $e / C_{\Sigma}$, where $\mathrm{e}$ is the elementary charge and $C_{\Sigma}$ is island capacitance. For large devices, this change in potential is negligible due to the high capacitance $C_{\Sigma}$. However, for nanometer-scale islands, $C_{\Sigma}$ is much smaller (about aF).

Change to SET island potential results an energy gap at the Fermi energy, preventing further electron tunneling. This phenomenon is called Coulomb blockade. It prevents current from flowing between source and drain $\left(I_{d s}=0\right)$, i.e, the SET is turned off. The Coulomb blockade effect can be overcome by changing the voltage of a conductor gate capacitively coupled to the island, thereby turning tunneling on or off.

As shown in Fig. 1A SET typically has three terminals. The source and drain terminals serve as electron reservoirs. When the SET is turned on, electrons tunnel from one terminal, through the junction, to the conductive island. They then tunnel through the other junction to the other terminal. Each tunneling junction is modeled as resistor $\left(R_{S}\right.$ or $\left.R_{D}\right)$ and capacitor $\left(C_{S}\right.$ or $\left.C_{D}\right)$ in parallel.
A gate terminal (G), with coupling capacitance $\mathrm{C}_{\mathrm{G}}$, controls the transport of electrons. The Coulomb blockade effect is maximized when $\mathrm{V}_{\mathrm{GS}}=\mathrm{me} / \mathrm{C}_{\mathrm{G}}$, where $m= \pm 1, \pm 2, \pm 3, \cdots$ because, at these voltages, the system is in minimum-energy state when an integer number of electrons are present on the island. The Coulomb blockade effect vanishes when = $\pm 1 / 2, \pm 3 / 2, \cdots$, i.e., when $m$ is a half-integer value because, at these voltages, the system is in a minimum-energy state when a half-integer number of electrons are present on the island. In this case, the single tunneling event does not move the system from a minimum energy state. Electrons can therefore tunnel, in single-file, through the island as determined by $\mathrm{V}_{\mathrm{DS}}$.

In order to observe the Coulomb blockade effect, the following constraints must be satisfied.

1) Since thermal fluctuations can suppress the Coulomb blockade effect, the electrostatic charging energy, $e^{2} / C_{\Sigma}$, must be much greater than $\mathrm{k}_{\mathrm{B}} \mathrm{T}$, where $\mathrm{k}_{\mathrm{B}}$ is Boltzmann's constant and $\mathrm{T}$ is the temperature. In order to ensure the reliability, $\quad e^{2} / C_{\Sigma} \geq k_{B} T \quad$ other more conservative, $e^{2} / C_{\Sigma} \geq 40 k_{B} T$ constraint is enforced. These equations imply that the maximum allowed island capacitance is inversely proportioned to temperature. At room temperature, an island capacitance below $1 \mathrm{aF}$ is required. Island capacitance is a function of island size. As shown in Table 1 room temperature operation requires an island size in the nanometer range, making fabrication challenging. At present, the smallest island capacitance of a fabricated device is around $0.15 \mathrm{aF}$ [9].

2) To observe single-electron charging effects, electrons must be confined to the island, which requires that the junction resistance must be higher than the quantum resistance, i.e., $\mathrm{R}_{\mathrm{S}}, \mathrm{R}_{\mathrm{D}}>$ $\mathrm{h} / \mathrm{e}^{2}, \mathrm{~h} / \mathrm{e}^{2}=25.8 \mathrm{k} \Omega$, where $\mathrm{h}$ is Plank's constant. Therefore, SETs have high resistances and low driving current.

Trang 207 


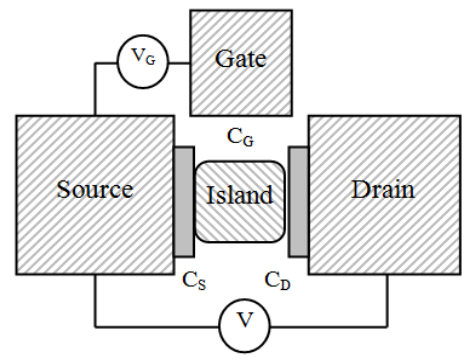

(A)

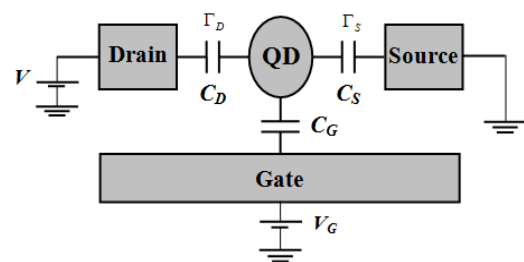

(B)

Figure 1. (A) Structure of SET, (B) equivalent schematic diagram of SET: $C_{G}$ - gate capacitance, $C_{S}$ - source tunnel junction capacitance, $C_{D}$ - drain tunnel junction capacitance, $R_{S}$ - source tunnel junction resistance, $R_{D}-$ drain

\section{Simulation method and results} tunnel junction resistance
From the point of view of fabrication methods, single electron transistors can be divided into two categories: SET with metallic island (namely metallic SET) and semiconducting island (namely semiconducting SET). SET's models can be also grouped in one level device and multi-level device.

We describe a SET's model for metallic SET using one-level device. We describe a SET's model for a multiple-level device (semiconducting SET) whose energy levels are described by a Hamiltonian matrix $[\mathrm{H}]$ and whose coupling to the source and the drain contacts is described by selfenergy matrices $\left[\Sigma_{1}(E)\right]$ and $\left[\Sigma_{2}(E)\right]$ respectively (Fig. 2).

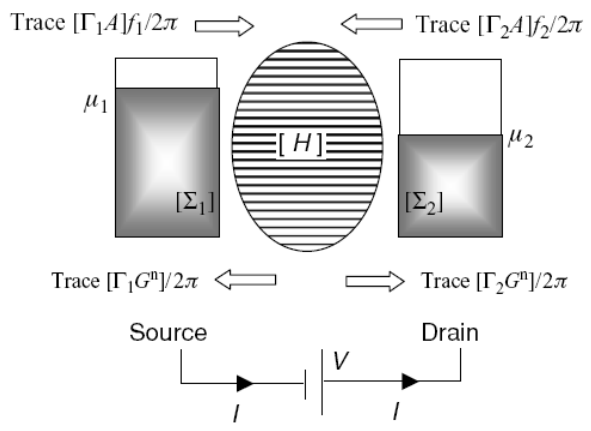

Fig. 2. Multi-level device whose energy levels are described by a Hamiltonian matrix $[\mathrm{H}]$ and whose coupling to the source and drain contacts is described by self-energy matrices $\left[\Sigma_{1}(E)\right]$ and $\left[\Sigma_{2}(E)\right]$ respectively
The flow of current is due to the difference in potentials between the source and the drain, each of which is in a state of local equilibrium, but maintained at different electro-chemical potentials $\mu_{1,2}$ and hence with two distinct Fermi functions:

$$
\begin{aligned}
& f_{1}(E)=\frac{1}{\exp \left[\left(E-\mu_{1}\right) / k_{B} T\right]+1} \\
& f_{2}(E)=\frac{1}{\exp \left[\left(E-\mu_{2}\right) / k_{B} T\right]+1}
\end{aligned}
$$

by the applied bias V: $\mu_{2}-\mu_{1}=-q V$. Here, Eenergy, $\mathrm{k}_{\mathrm{B}}$ - Boltzmann constant, $\mathrm{T}$ - temperature. The density matrix is given by $\rho=\int_{-\infty}^{+\infty} \frac{d E}{2 \pi} G^{n}(E)=\int_{-\infty}^{+\infty} \frac{d E}{2 \pi}\left[A_{1}(E) f_{1}(E)+\right.$ $\left.A_{2}(E) f_{2}(E)\right]$

The current $I_{D}$ flows in the external circuit is given by Landauer formula [18]:

$$
I_{D}=(q / h) \int d E T(E)\left(f_{1}(E)-f_{2}(E)\right)
$$

The quantity $\mathrm{T}(\mathrm{E})$ appearing in the current equation (4) is called the transmission function, which tells us the rate at which electrons transmit from the source to the drain contacts by propagating through the device. Knowing the device Hamiltonian $[\mathrm{H}]$ and its coupling to the contacts described by the self-energy matrices $\Sigma_{1,2}$, we can calculate the current from (4). For coherent transport, one can calculate the

\section{Trang 208}


transmission from the Green's function method, using the relation:

$$
\begin{aligned}
T(E)=\operatorname{Trace}[ & \left.\Gamma_{1} G \Gamma_{2} G^{+}\right] \\
& +\operatorname{Trace}\left[\Gamma_{2} G \Gamma_{1} G^{+}\right]
\end{aligned}
$$
obtained:

The appropriate NEGF equations are

$$
\begin{gathered}
\mathrm{G}=\left[\mathrm{EI}-\mathrm{H}-\Sigma_{1}-\Sigma_{2}\right]^{-1}, \Gamma_{1,2}=\mathrm{i}\left[\Sigma_{1,2}-\Sigma_{1,2}^{+}\right], \mathrm{A}_{1}(\mathrm{E})=\mathrm{GI}, \\
\mathrm{G}^{\mathrm{n}}=\left[\mathrm{A}_{1}\right] \mathrm{f}(\mathrm{E})+\left[\mathrm{A}_{2}\right] \mathrm{f}(\mathrm{E}), \\
\mathrm{A}=\mathrm{i}\left[\mathrm{G}-\mathrm{G}^{+}\right]=\left[\mathrm{A}_{1}\right]+\left[\mathrm{A}_{2}\right]
\end{gathered}
$$

Where $\mathrm{H}$ is effective mass Hamiltonian, $\mathrm{I}$ is an identity matrix of the same size, $\Gamma_{1,2}$ are the broadening functions, $\mathrm{A}_{1,2}$ are partial spectral functions, $A(E)$ are spectral function, $G^{n}$ is correlation function. We use a discrete lattice with $\mathrm{N}$ points spaced by lattice spacing "a" to calculate the eigen-energies for electrons in the quantum dot.

By utilizing the simulator namely NEMOVN2 [19], the $I_{D}-V_{G}$ characteristics of SET having the given parameters are shown in Fig. 3.
Fig. 3 demonstrates the typical Coulomb oscillation behavior in SET $I_{D}-V_{G}$ characteristics. It shows that the SET Coulomb oscillation period ( $\mathrm{e} / \mathrm{C}_{\mathrm{G}}$, e is the electronic charge) is dictated by SET's gate capacitance. Values of gate voltage at the first and the second peaks are $\mathrm{e} / 2 \mathrm{C}_{\mathrm{G}}(80 \mathrm{mV})$ and $3 \mathrm{e} / 2 \mathrm{C}_{\mathrm{G}}(240 \mathrm{mV})$ respectively. Here, it should be emphasized that the peak and the valley currents of Coulomb oscillations are perfectly represented by the model. The results calculated according to model $\left(\mathrm{e} / 2 \mathrm{C}_{\mathrm{G}}\right.$ for $\left.\mathrm{C}_{\mathrm{G}}=1 \mathrm{aF}\right)$ coincide well with the simulated ones. Current-voltage $\left(\mathrm{I}_{\mathrm{D}^{-}}\right.$ $V_{G}$ ) characteristics showed the suppression of the Coulomb oscillation by broadening current peaks increased at high $\mathrm{V}_{\mathrm{D}}(200 \mathrm{mV})$. It also reveals the fact that it is difficult to obtain the Coulomb oscillations in the device characteristics at high $\mathrm{V}_{\mathrm{D}}$ greater than $3 \mathrm{e} / \mathrm{C}_{\mathrm{T}}\left(\mathrm{C}_{\mathrm{T}}\right.$ is the total capacitance of SET), $(160 \mathrm{mV})$. It should note that high drain voltage, $V_{D}$ undermines SET's current-voltage characteristics. Characteristics of metallic and semiconducting SET are shown in Fig. 3A and 3B respectively.

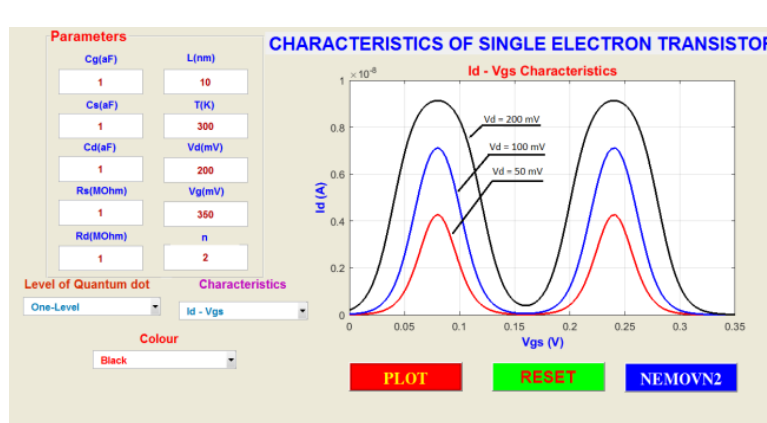

(A)

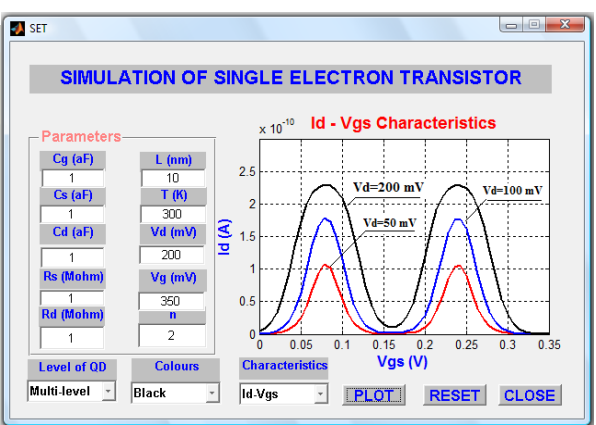

(B)

Fig. 3. Typical $I_{D}-V_{G}$ characteristics (Coulomb oscillations) of SET simulated by the simulator NEMO-VN2 for various values of $\mathrm{V}_{\mathrm{D}}=50 \mathrm{mV}, 100 \mathrm{mV}$ and $200 \mathrm{mV}$ at room temperature, $\mathrm{T}=300 \mathrm{~K}$. The SET parameters are: $\mathrm{L}=$ $10 \mathrm{~nm}, \mathrm{C}_{\mathrm{G}}=\mathrm{Cs}_{\mathrm{S}}=\mathrm{C}_{\mathrm{D}}=1 \mathrm{aF}$ and $\mathrm{Rs}_{\mathrm{S}}=\mathrm{R}_{\mathrm{D}}=1 \mathrm{M} \Omega$ : A) one level SET, B) Multi-level SET

Fig. 4 reproduces SET's $I_{D}-V_{D}$ characteristics at room temperature $(\mathrm{T}=300 \mathrm{~K})$ for different gate biases, $\mathrm{V}_{\mathrm{G}}=0 \mathrm{mV}$ and $\mathrm{V}_{\mathrm{G}}=\mathrm{e} / 2 \mathrm{C}_{\mathrm{G}}$ (Coulomb oscillation). Characteristics of metallic and semiconducting SET are shown in Fig. 4A and 4B respectively. 
SCIENCE \& TECHNOLOGY DEVELOPMENT JOURNAL:

NATURAL SCIENCE, VOL 1, ISSUE 6, 2017

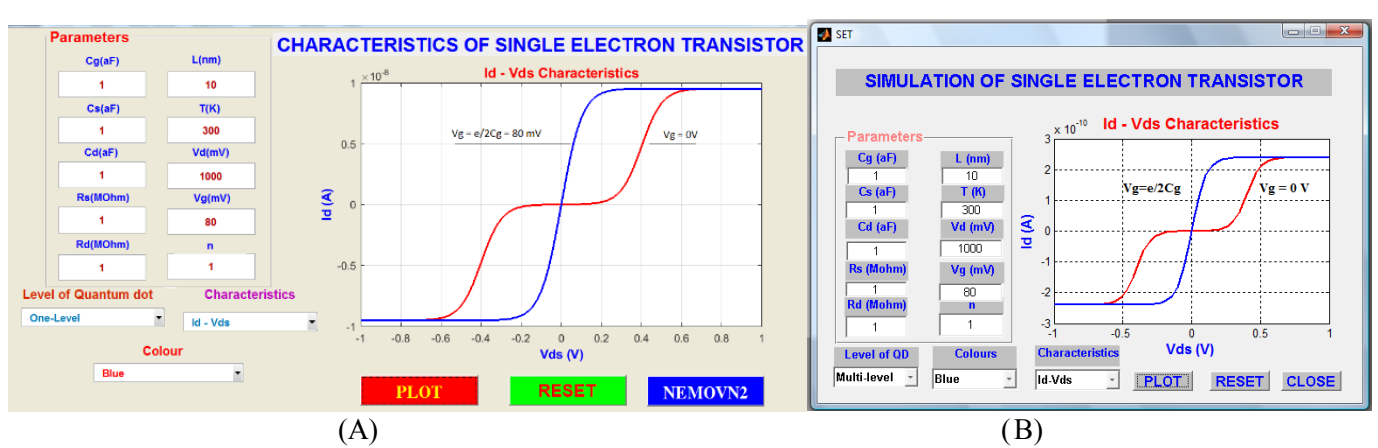

Fig. 4. $I_{D}-V_{D}$ characteristics simulated by the simulator at room temperature $T=300 \mathrm{~K}$ for various values of $V_{G}=0$ $\mathrm{mV}$ and $\mathrm{V}_{\mathrm{G}}=\mathrm{e} / 2 \mathrm{C}_{\mathrm{G}}$. The SET parameters are: $\mathrm{L}=10 \mathrm{~nm}, \mathrm{C}_{\mathrm{G}}=\mathrm{CS}_{\mathrm{S}}=\mathrm{C}_{\mathrm{D}}=1 \mathrm{aF}$ and $\mathrm{Rs}_{\mathrm{S}}=\mathrm{R}_{\mathrm{D}}=1 \mathrm{M} \Omega$ : A) One-level SET, B) Multi-level SET

For $\mathrm{V}_{\mathrm{G}}=0 \mathrm{mV}, \mathrm{V}_{\mathrm{D}}$ starts from the Coulomb blockade region and increases (or decreases) through the single-electron tunneling region. For $\mathrm{V}_{\mathrm{G}}=\mathrm{e} / 2 \mathrm{C}_{\mathrm{G}}$ (at the first Coulomb oscillation peak), $\mathrm{I}_{D}$ starts from zero and increases (or decreases) linearly. The threshold voltage of SET is $\mathrm{V}_{\mathrm{G}}=$ $\mathrm{e} / 2 \mathrm{C}_{\mathrm{G}}$.

Fig. 5 represents $I_{D}-V_{G}$ characteristics with the value of $V_{D}=10 \mathrm{mV}$ at different temperatures. One can note that the effects of temperature on Coulomb oscillations are strongly. The Coulomb oscillations of SET are clear at low temperature (at
$50 \mathrm{~K})$. Current-voltage $\left(\mathrm{I}_{\mathrm{DS}}-\mathrm{V}_{\mathrm{G}}\right)$ characteristics showing the suppression of the Coulomb oscillation by broadening current peaks increased at higher temperature $(100 \mathrm{~K}, 200 \mathrm{~K}$, and $300 \mathrm{~K})$. It also reveals the fact that it is no more possible to obtain the Coulomb oscillations in the device characteristics at high temperature. It should note that high temperature undermines SET's currentvoltage characteristics.

Characteristics of metallic and semiconducting SET are shown in Fig. 5A and 5B respectively.

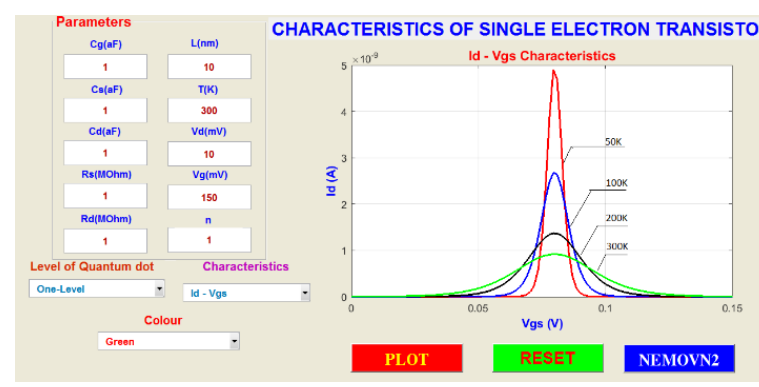

(A)

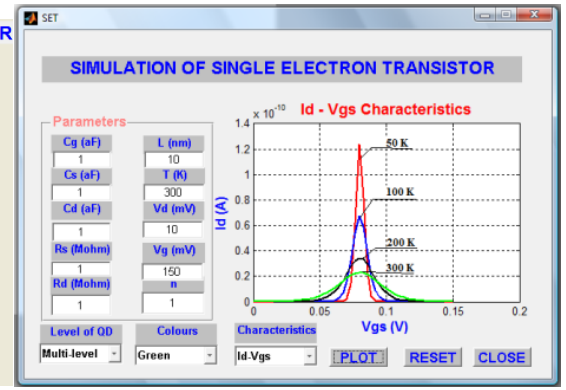

(B)

Fig. 5. Typical $I_{D}-V_{G}$ characteristics simulated by the simulator for value of $V_{D}=10 \mathrm{mV}$ at different temperatures: $50 \mathrm{~K}, 100 \mathrm{~K}, 200 \mathrm{~K}, 300 \mathrm{~K}$. The SET device parameters are: $\mathrm{L}=10 \mathrm{~nm}, \mathrm{C}_{\mathrm{G}}=\mathrm{C}_{\mathrm{S}}=\mathrm{C}_{\mathrm{D}}=1 \mathrm{aF}$ and $\mathrm{R}_{\mathrm{S}}=\mathrm{R}_{\mathrm{D}}=1 \mathrm{M} \Omega: \mathrm{A}$ ) One-level, B) Multi-level

The effect of temperature $(\mathrm{T})$ on the device characteristics is also demonstrated in Fig. 6, and it shows that the Coulomb blockade region becomes thinner at higher temperatures. Therefore, an accurate model for SET simulation must capture both the effect of temperature and the effect of high $V_{D}$ on the device characteristics. Characteristics of metallic and semiconducting SET are shown in Fig. 6A and 6B respectively.

\section{Trang 210}


TẠP CHÍ PHÁT TRIỂN KHOA HỌC \& CÔNG NGHỆ: CHUYÊN SAN KHOA HỌC TỤ’ NHIÊN, TậP 1, SỐ 6, 2017

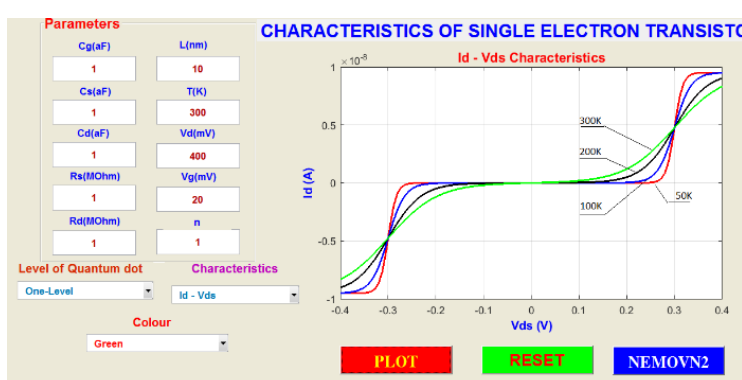

(A)

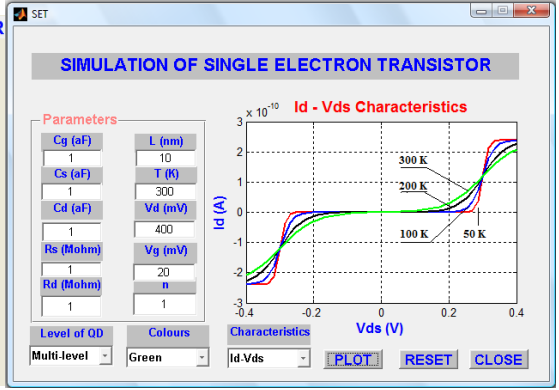

(B)

Fig. 6. Typical $I_{D S}-V_{D S}$ characteristics simulated by the simulator for value of $V_{G}=20 \mathrm{mV}$ at different temperatures (T): $50 \mathrm{~K}, 100 \mathrm{~K}, 200 \mathrm{~K}$, and $300 \mathrm{~K}$. The SET device parameters are: $\mathrm{L}=10 \mathrm{~nm}, \mathrm{C}_{\mathrm{G}}=\mathrm{Cs}_{\mathrm{S}}=\mathrm{C}_{\mathrm{D}}=1 \mathrm{aF}$ and $\mathrm{R}_{\mathrm{S}}=\mathrm{R}_{\mathrm{D}}=1$ $\mathrm{M} \Omega$ : One-level SET, Multi-level SET

Accuracy of the model is evaluated by comparing simulated results with experimental ones from [8].

According to the work [8], its authors have succeeded in fabricating an SET. The SET operates at room temperature, showing a clear Coulomb staircase with a $\sim 150 \mathrm{mV}$ period at 300 $\mathrm{K}$. The drain current-voltage characteristics of the SET were measured at room temperature and are shown in Fig. 7A. The gate bias was set to 2 V. In the Figure, the solid lines show the current of the SET, and the dashed line shows the conductance of the SET. Between the drain bias of $0 \mathrm{~V}$ and $0.75 \mathrm{~V}$, four clear Coulomb staircases with a $\sim 150$ $\mathrm{mV}$ period are observed. The drain current versus gate bias characteristics with $150 \mathrm{mV}$ drain bias at room temperature exhibit clear current oscillations with a period of $\sim 460 \mathrm{mV}$, implying a periodic Coulomb oscillation of the current. Fig. 7B, C reproduce $I_{D}-V_{D}$ characteristics and conductance of the same SET having length, $\mathrm{L}=10 \mathrm{~nm}$ at temperature of $300 \mathrm{~K}$. Fig. 7B, C show simulated results of $I_{D}-V_{D}$ characteristics and conductance of the same SET.
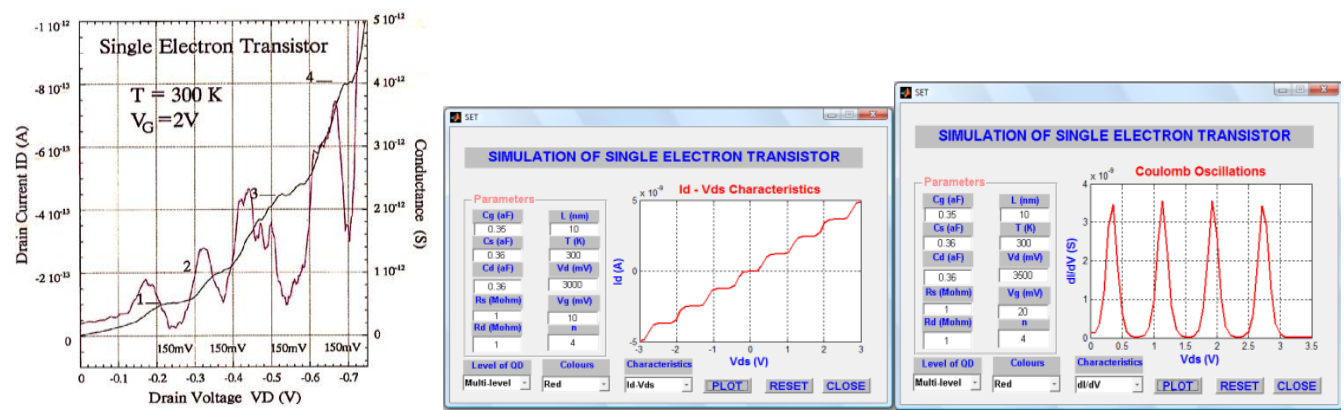

A)

B) C)

Fig. 7. A) Drain current versus drain voltage characteristics of the $S E T$ at $300 \mathrm{~K}[8]: \mathrm{V}_{\mathrm{D}}=150 \mathrm{mV}, \mathrm{C}_{\mathrm{t}}=0.36 \mathrm{aF}$,

$\mathrm{C}_{\mathrm{G}}=0.35 \mathrm{aF}$; B) $\mathrm{I}_{\mathrm{D}}-\mathrm{V}_{\mathrm{D}}$ characteristics simulated; C) Conductance characteristics simulated by the simulator,

NEMO-VN2 for value of $\mathrm{V}_{\mathrm{G}}=20 \mathrm{mV}$. The SET device parameters are: $\mathrm{L}=10 \mathrm{~nm}, \mathrm{C}_{\mathrm{G}}=0.35 \mathrm{aF}, \mathrm{Cs}_{\mathrm{S}}=\mathrm{C}_{\mathrm{D}}=0.36$ $\mathrm{aF}$ and $\mathrm{R}_{\mathrm{S}}=\mathrm{R}_{\mathrm{D}}=1 \mathrm{M} \Omega$

Four clear Coulomb staircases are shown in simulated results on $\mathrm{I}_{\mathrm{D}}-\mathrm{V}_{\mathrm{D}}$ characteristics (Fig. 7B). Four clear conductance peaks are also shown in Fig. 7C. The results simulated according to the model coincide well with the experimental ones at least in the same shape.

Trang 211 


\section{CONCLUSION}

Physical properties, fabrication, and the most popular simulators of SET have been introduced. A model for SET device using NEGF written in GUI of Matlab had been reported. The proposed model had been verified at one-level and multiplelevel for SET's device. A set of simulations is then successfully performed for various parameters of the SET's device in one-level and multi-level modes. The model is not only able to accurately describe $I_{D}-V_{G}, I_{D}-V_{D}$ SET's characteristics, but also affects of gate materials, size of SET, and temperature on SET's characteristics. Different SET's device characteristics $\left(\mathrm{I}_{\mathrm{D}}-\mathrm{V}_{\mathrm{G}}, \mathrm{I}_{\mathrm{D}}-\mathrm{V}_{\mathrm{D}}\right.$, effect of temperature) have been simulated. We have found that currents in metallic SET are greater than in semiconducting SET about 100 times. The simulated results are also compared with experimental ones [8] and good agreements are validated.

\section{Một số kết quả về tính chất vật lý của transistor đơn điện tử}

- Lê Hoàng Minh

Trường Đại học Sư phạm Kỹ thuật TP. HCM

- Đinh Sỹ Hiền

Trường Đại học Khoa học Tự nhiên, ĐHQG-HCM

\section{TÓM TÁT}

Transistor đơn điện tủ (SET) là một yếu tố co bản trong lĩnh vưc nghiên cúu về điện tủ nano và công nghệ nano hiện nay. SET cho kich thước đặc tính nano, tiêu tốn công suất thấp và tốc độ làm việc cao. SET là một linh kiện chuyển mạch thang nano mới; có thể điều khiển chuyển động của một điện tử. Mục tiêu của bài báo này là bàn về tính

chất vật lý của SET và tập trung lên mô phỏng đặc trung luợng tủ co bản của linh kiện nhu hiệu ứng xuyên hầm, khóa Coulomb, chấm lương tủ, bậc thang Coulomb và dao động Coulomb. Nhũng đặc trung dòng-thế được nghiên cứu kỹ để minh họa. Hai loại SET kim loại và bán dẫn đã được mô phỏng.

Tù khóa: transistor đơn điện tử, đặc trung dòng-thế, khóa Coulomb, bậc thang Coulomb, dao động Coulomb

\section{REFERENCES}

[1]. International technology roadmap for semiconductors, http://public.itrs.net(2006).

[2]. D.V. Averin, K.K. Likharev, Coulomb blockade of tunneling and coherent oscillations in small tunnel junctions, J. Low Temperature Physics, 62, 345-372 (1986).

[3]. T.A. Fulton, J.G. Dolan, Observation of single electron charging effects in small tunnel junctions, Physics Review Lett., 59, 109-112 (1987).
[4]. K.K. Likharev, Single electron devices and their applications, Proc. IEEE, 87, 606-632, (1999).

[5]. Y. Nakamura, C.D. Chen, J.S. Tsai, $100 \mathrm{~K}$ operation of Al-based single electron transistors, Japan Journal of Applied Physics, 35, 1465-1467 (1996).

[6]. X. Tang, X. Baie, V. Bayot, F. Van de Wiele, J. P. Colinge, An SOI single electron transistor, Proceedings of Silicon on Insulator Conference, Oct. 1999, 46-47 (1999).

Trang 212 
[7]. M. Ahlskog, R Tarkiainen, L. Roschier, P. Hakonen, Single electron transistor made of two crossing multi-walled carbon nanotubes and its noise properties, Applied Physics Lett., 77, 4037-4039 (2000).

[8]. K. Matsumoto, M. Ishii, K. Segawa, Y. Oka, B.J. Vartanian, J.S.Harris, Room temperature operation of a single electron transistor made by the scanning tunneling microscope nanooxidation process for the TiO/Ti system, Appl. Phys. Lett. 68, 34 (1996): doi:101063/1, 116747.

[9]. J.I. Shirakashi, K. Matsumoto, N. Miura, M. Kanagai, Single electron charging effects in $\mathrm{Nb} / \mathrm{Nb}$ oxide-based single electron transistor at room temperature, Applied Physics Lett. 72, 15, 1893-1895 (1998).

[10]. Y.A. Pashkin, Y. Nakamura, J.S. Tsai, Room-temperature Al single electron transistor made by electron beam lithography, Applied Physics Lett. 76, 16, 2256-2258 (2000).

[11]. J.R. Heath, M. A. Ratner, Molecular electronics, Physics Today, 56, 43-49 (2003).

[12]. A.K. Geim, K.S. Novoselov, The rise of grapheme, Nature materials, 6, 183-191 (2007).

[13]. C. Wasshuber, Computational Electronics, New York: Springer-Verlag (2002).
[14]. R.H. Chen, A.N. Karotkov, K.K. Likharev, A new logic family based on single electron transistors, Proceedings of Device Res. Conf., 44-45, Charlottesville, 19-21 June 1995.

[15]. K. Uchida, R. Matsuzawa, J. Koga, R. Ohba, S. Takagi, A. Toriumi, Analytical single electron transistor (SET) model for design and analysis of realistic SET circuits, Jpn.J. Appl. Phys., 39, 2321-2324 (2000).

[16]. H. Inokawa, Y. Takashi, A compact analytical model for asymmetrical singleelectron transistors, IEEE Transactions on Electron Devices, 50, 2, 455-461 (2003).

[17]. S. Mahapatra, V. Vainish, C. Wasshuber, K. Banerjee, A. M. Ionescu, Analytical modeling of single electron transistor (SET) for hybrid CMOS-SET analog IC design, IEEE Trans. Electron Devices, 51, 11, 17721782 (2004).

[18]. S. Datta, Quantum Transport: Atom to Transistor, Cambridge University Press (2005).

[19]. D.S. Hien, Development of quantum device simulator, NEMO-VN2, Proceedings of fifth IEEE international symposium on electronic design, test and applications, DELTA-2010, 13-15 January 2010, Ho Chi Minh City, 170-173 (2010). 